\title{
CORRECTION
}

View Article Online

View Journal I View Issue

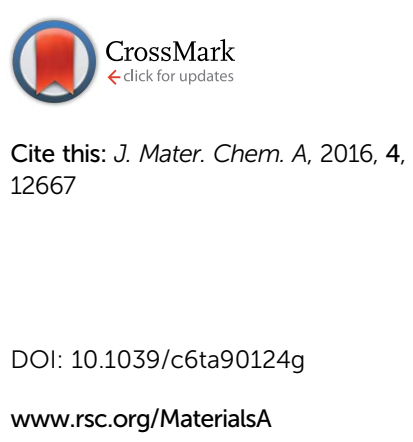

\section{Correction: Improving the efficiency of polymer solar cells via a treatment of methanol : water on the active layers}

Biao Guo, Weilong Zhou, Mengchun Wu, Junjie Lv, Chengzhuo Yu, Fenghong Li* and Zhonghan $\mathrm{Hu}$

Correction for 'Improving the efficiency of polymer solar cells via a treatment of methanol : water on the active layers' by Biao Guo et al., J. Mater. Chem. A, 2016, DOI: 10.1039/c6ta04026h.

There is a footnote in the original manuscript for all authors of the author list stating that "these authors contributed equally" however $80 \%$ of the work was done by the first author, Biao Guo.

The Royal Society of Chemistry apologises for these errors and any consequent inconvenience to authors and readers. 